\title{
La course à l'excellence dans la publication scientifique
}

Dernière mise à jour : 3 janvier 2018

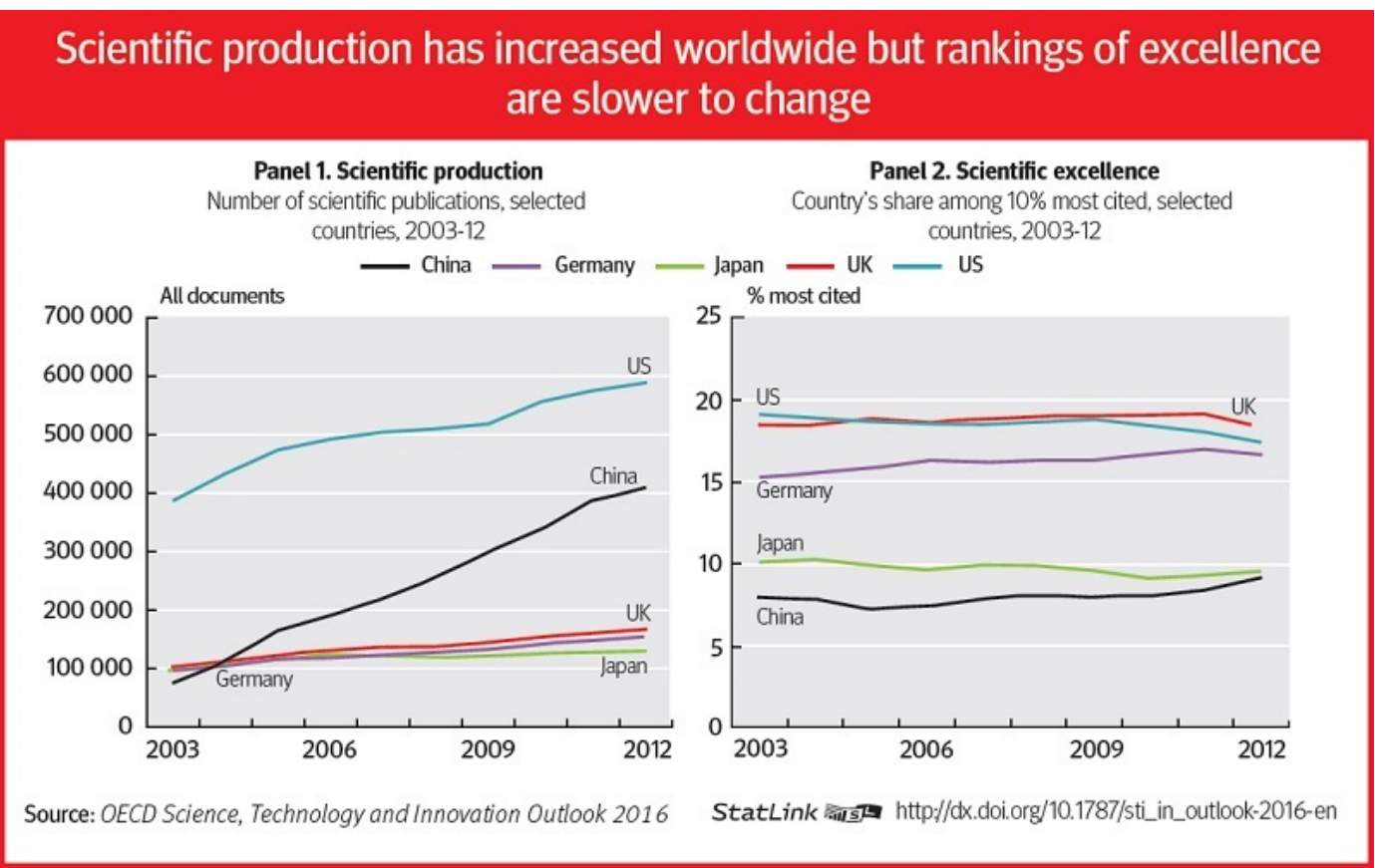

Qualité vaut mieux que quantité, disait le philosophe romain Sénèque. Selon des données récentes sur les citations, cette maxime pourrait bien s'appliquer à la production scientifique. Entre 2003 et 2012, le nombre total des travaux scientifiques publiés chaque année en Allemagne, en Chine, aux États-Unis, au Japon et au Royaume-Uni a doublé, passant de 765000 à près de 1.5 million, sous l'effet de la hausse de l'investissement dans la recherche publique. Les États-Unis dominent ce classement en volume, bientôt rattrapés par la Chine.

Au cours de cette période, si la Chine a quadruplé sa production scientifique, sa part dans les $10 \%$ des publications les plus citées n'a que légèrement augmenté. L'Allemagne a connu une progression analogue sur la voie de l'excellence, malgré une production nettement moins importante en volume. Les États-Unis ont été détrônés par le Royaume-Uni au regard de la part de leurs travaux parmi les plus 
cités, bien que le nombre de leurs publications scientifiques ait augmenté de moitié.

Dans le classement mondial de l'excellence scientifique, les universités du peloton de tête se trouvent aux États-Unis et au Royaume-Uni, tandis que celles de l'Allemagne et de la Chine progressent. La position de ces pays dépendra probablement à l'avenir de leur capacité à attirer des étudiants de diverses régions du monde. L'ouverture compte autant que la qualité.

\section{Références}

La course à l'excellence dans la publication scientifique http://dx.doi.org/ 10.1787/sti_in_outlook-2016-en 